American Journal of Biochemistry and Biotechnology 4 (4): 416-421, 2008

ISSN 1553-3468

(C) 2008 Science Publications

\title{
A Review on Correlations between Fish Freshness and pH during Cold Storage
}

\author{
K.A. Abbas, A. Mohamed, B. Jamilah and M. Ebrahimian \\ Faculty of Food Science and Technology, University Putra Malaysia, Malaysia
}

\begin{abstract}
Freshness of fish in most markets was found to be the significant quality parameter. The state of fish freshness was assessed by various methods but most of them were costly, time-consuming and not user friendly tools which made the development of simple, easy, undemanding and reliable system for the evaluation of fish freshness unresolved goal. The findings of many researchers revealed that there was remarkable correlation between the $\mathrm{pH}$ and the fish freshness which suggested that this physical characteristic could be used as suitable tool for the analysis and fish freshness evaluation rather than sensory evaluation method which inherent many uncertainties. Based on this demand, this paper was established with the objective of reviewing the literature which focused on the $\mathrm{pH}$ as one of the simple and reliable freshness indicator for cold stored fish samples.
\end{abstract}

Key words: Freshness, pH, sensory evaluation, cold storage, fish

\section{INTRODUCTION}

Fish quality is a complex concept involving a whole range of factors which for the consumer include for example: safety, nutritional quality, availability, convenience and integrity, freshness, eating quality and the obvious physical attributes of the species, size and product type. Information about handling, processing and storage techniques, including time/temperature histories that can affect the freshness and quality of the products is very important for the partners in the chain. Additionally, seasonal condition, that affect the fishing grounds and capture methods and the occurrence of various quality defects influence the overall quality. One of the most unique characteristics of fish as food is that it is a highly perishable commodity. Consequently time passed after catch and the temperature 'history' of fish is very often the key factor determining the final quality characteristics of fish products ${ }^{[1]}$.

Sensory assessment has always played a key role in quality and freshness evaluation in the fish industry. The various sensory characteristics, such as outer appearance, odour and colour are still very important in the quality systems in the fish processing industry. Sensory inspection of processed fish is used in the fish industry to find defects that have occurred during handling and processing ${ }^{[2]}$.

Recently Some researchers ${ }^{[3]}$ determined the shelf life and freshness of stored at $0-10^{\circ} \mathrm{C}$ for 28 days and have found that from sensory and $\mathrm{pH}$ point of view under various storage temperatures, the higher the storage temperature the faster is the increase in both sensory and $\mathrm{pH}$ values which can be used as measurements for quality deterioration and shelf life prediction in the fish marketing sector. Fresh water fish (Pangasius sutchi) Since relatively low $\mathrm{pH}$ value of cold storage fish encountered $24 \mathrm{~h}$ after harvesting reflected the good nutritional state of the fish, it can be used as good freshness instrumental tool. It was found that there a high degree of association was observed between $\mathrm{pH}$ of the flesh and either $\log \mathrm{CFU} / \mathrm{g}\left(\mathrm{R}^{2}=\right.$ $0.99)$, trimethyamine (TMA) content $\left(\mathrm{R}^{2}=0.96\right)$, or TVBN level $\left(R^{2}=0.97\right)$ in the spoiling fish $^{[4]}$. Accordingly, this review paper has been justified.

Fish freshness: The shelf life of freshly harvested fish depends on the bacterial flora, storage temperature, handling and physiological condition of fish. The shelf life reflects the quality of the final fish product either fresh or processed. The quality of fish can be estimated by sensory tests, microbial methods, measuring volatile compounds and lipid oxidation, determination of changes in muscle proteins, ATP breakdown products and physical changes (including electrical properties of skin) in fish. They may include mathematical models to predict remaining shelf life for the fishing industry, trade and food inspection officials. However, there are variations depending on age, sex, environment, feed intake and season. Quality parameters may be physical changes such as consistency, water content or colour, or they may be biochemical changes such as changes in lipids, proteins or enzymes ${ }^{[5]}$.

Corresponding Author: Kassim A. Abbas, lecturer in Department of Food Technology, Faculty of Food Science and Technology, , UPM, Malaysia, Tel: +603-89418534, Fax +603-89423552 


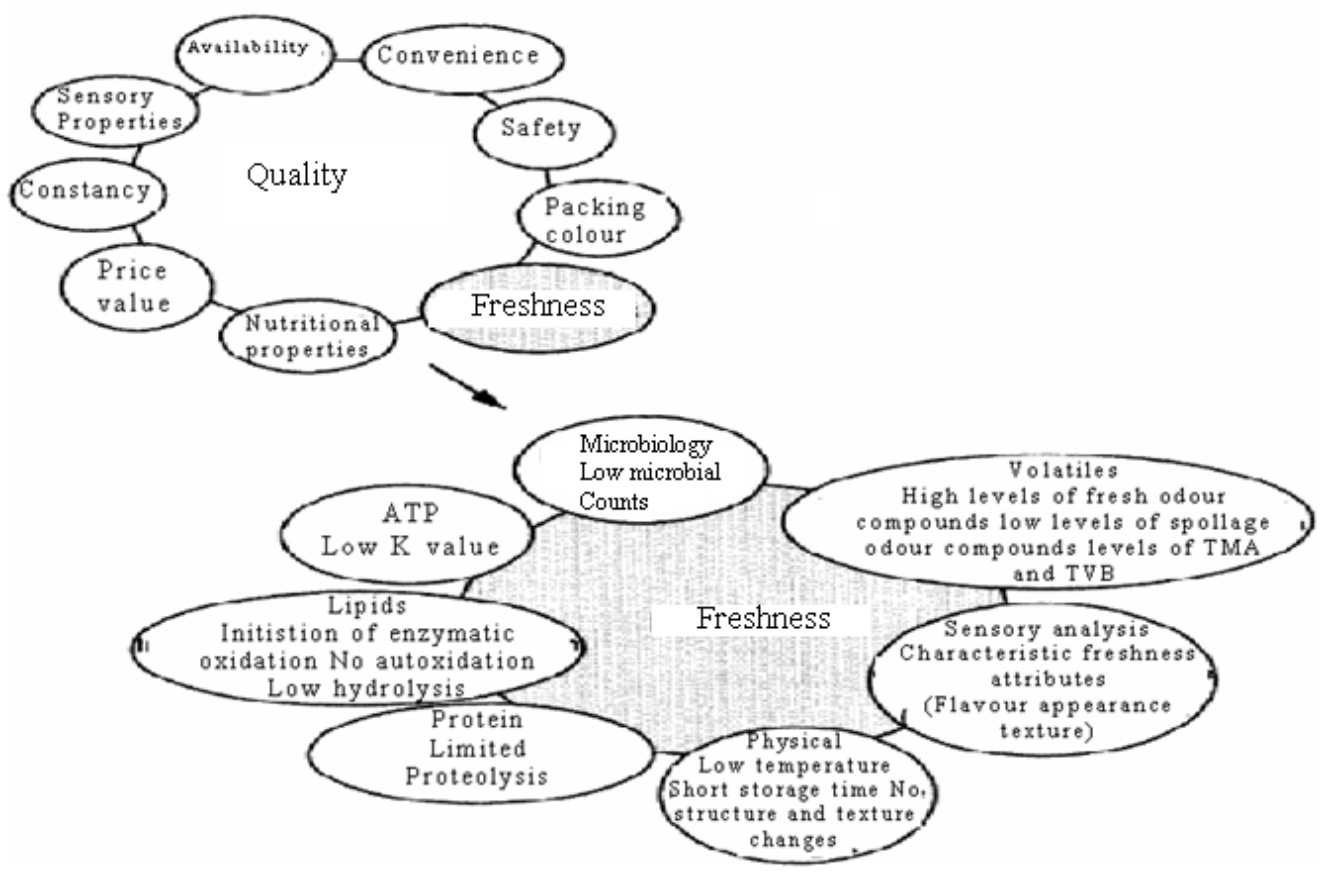

Fig. 1: The relationship between quality and freshness.

Fish freshness is fundamental to fish quality. The state of freshness can be described by a variety of definite properties of the fish which can be assessed by various indicators $^{[6]}$. These properties, and thus the freshness and quality of the end product, are dependent on different biological and processing factors that influence the degree of various physical, chemical, biochemical and microbiological changes occurring post mortem in fish ${ }^{[1]}$.

Freshness makes a major contribution to the quality of fish or fishery products. For all kinds of products, freshness is essential for the quality of the final product. Figure 1 depicts the relationship between quality and freshness, focusing on the different characteristics of freshness as approached by the different subgroups of the projects.

Freshness can be explained to some extent by some objective sensory, (bio) chemical, microbial and physical parameters and can therefore be defined as an objective attribute which must show normal odour, flavor, appearance and texture characteristics of the species to be used for samples. ${ }^{[7]}$. The human senses play a fundamental role in this assessment, which we call sensorial evaluation ${ }^{[8]}$.

Sensorial evaluation of the freshness of fish: Sensory evaluation is defined as the scientific discipline used to evoke, measure, analyse and interpret characteristics of food as perceived by the senses of sight, smell, taste, touch and hearing. Sensory test can be divided into three groups: discriminative tests, which indicate whether there is a difference between samples; descriptive tests and affective tests. Discriminative and descriptive tests are objective analytical tests in which a trained panel is used. Affective tests are subjective consumer tests that are based on a measure of preference or acceptance. The choice of method depends on purpose of the application of the sensory evaluation and whether it is used in product development, quality control, consumer studies or research. The most commonly used descriptive tests are structured scaling for quality assessment and profiling for a detailed description of one or more attributes.

Quality is a function of freshness; freshness is essential for quality but it is not a priori a quality factor. The upper 'quality' circle comprises the factors that contribute to quality, and the 'lower' freshness circle details the various approaches used to evaluate fish freshness. The $\mathrm{K}$ value is defined as the ratio of the sum of inosine and hypoxanthine concentrations to the total concentration of adenosine troposphere (ATP) metabolites.

Characteristics sensory changes occur in the appearance, odour, taste and texture of fish when they deteriorate. In Europe, the commonly used method for the quality assessment of raw fish in the inspection service and in the fishing industry is the European Union Scheme. This scheme does not take into account differences between species because only general parameters are used. Alternative scaling methods such 
as the Quality Index Methods (QIM) have been suggested, where the descriptions of the individual grades are precise, objective, independent and primary rather than a cluster of terms. The QIM is based on the significant sensory parameter of raw fish. The scores for all the characteristics are added to give an overall sensory score, the so-called quality index, which can also be used to predict storage life. In the fish industry, the grading of the raw fillets also occurs. However, it is more common to cook fillets before carrying out sensory evaluation and the Torry scheme is the most commonly used scale for the freshness evaluation of cooked fish, both in the fish industry and in the research laboratories throughout Europe.

In the fish industry, a few highly specialized trained assessors usually evaluate the freshness of fish. Guidelines for the sensory evaluation of fish and shellfish in inspection and regulation services are currently under discussion by the Codex Committee on Fish and Fishery Products. The sensory evaluation of food has been described with the establishment of quality control programmes in mind. In research laboratories, it is common to have trained panels with proven skills, complete sensory evaluation facilities and computerized data sampling. Some of the food research laboratories studying the quality of fish have received an accreditation for their sensory evaluation methods based on the EN 45001 and the ISO.IEC Guide 25. The ISO standards describe both the selection and training of panellists ${ }^{[7]}$.

Sensory test: Advantages and disadvantages: The sensory test is the oldest and still most widespread and good mean of evaluating the acceptability and edibility of fish. It depends on human senses, e.g. smell and sight, supplemented by taste and touch. The reasons for the preferential use of sensory tests are obvious: no special laboratory equipment is needed, the fish can be examined wherever they happen to be, the tests can be carried out quickly, and many samples can be evaluated in a relatively short time.

The uncertainty and difficulties of sensory judgment of fish freshness have been recognized by those in the field. Ansari and others ${ }^{[9]}$ assured the necessity of establishing new digital scale by which the freshness of Malaysian patin fish could be determined via measuring thermal properties rather than sensory test. Wilkie and his co-workers ${ }^{[10]}$ highlighted the uncertainty inherent in organoleptic test when he applied that test on Australian fragrant, imported fragrant and non-fragrant rice aroma. He used a large number of panellists of mixed age, genders and cultural background. He reported that the female were better than the male, and the Australian was better than nonAustralian at distinguishing between the aroma of fragrant and non-fragrant rice. Subjects in the 13-18 year old category were better than younger and older age group at distinguishing between the Australian fragrant and non-fragrant rice while those 19 year old and older were better than others at distinguishing between the Australian fragrant and imported-fragrant. In this regard, it was mentioned ${ }^{[11]}$ that sensory methods are fast, simple, sensitive and objective. But they rely on human judgment and proper training of panels.

To overcome some of the disadvantages associated with sensory judgment, attempts have been made to minimize the personal uncertainties and to overcome the qualitative nature of the test by means of trained or experienced panels to judge the samples, and by the elaboration of numerical systems of scoring and recording the sensory judgments.

Instrumental methods as tools for fish freshness determination: Several instrumental techniques have been introduced in the recent past to measure physical, chemical and biological parameters of fishes such as spectrophotometers, texture meters, image analysers, colorimeters, devices to test surface electrical properties and electronic noses.

Among the plenty of instrumental approaches, some may be considered as natural candidate to replace human senses. To this regard the following can be mentioned: texture analysis for firmness, electronic nose for odour and colorimeter for skin image coherence for skin appearance.

The relationship of the instrument with freshness is well known. Indeed, physical properties, as firmness and skin appearance are strictly restricted to storage days because of cellular flaking of autolytic and microbial changes. In fact, the most obvious fish change, after capture is rigor mortis due to a loss of the elastic texture of the muscle; this condition usually last for a day or more in iced fish, then rigor resolves. The brightness and the appearance of the mucus on the skin are strictly related to freshness as well. On the other hand, fresh fish odour is due to the high number of volatile compounds changing in time with fish spoiling. In fact, the flesh of fresh fish is practically odourless and any different odour it smells results from both environmental activity release oxidized fats (rancidity) and produced various amines, volatile sulphur compounds, aldehydes, ketons, esters and hypoxanthine, as well as other low molecular weight molecules.

Texture analyzer, colorimeter and electronic nose can be calibrated in order to provide the estimation of the correspondent human sense and their estimation can be treated as QIM attributes and used to build a quality score that behaves like the QIM towards the storage time at $0^{0} \mathrm{C}$. We call this score "Artificial Quality Index" (AQI) ${ }^{[12]}$. 
Am. J. Biochem. \& Biotech., 4 (4): 416-421, 2008

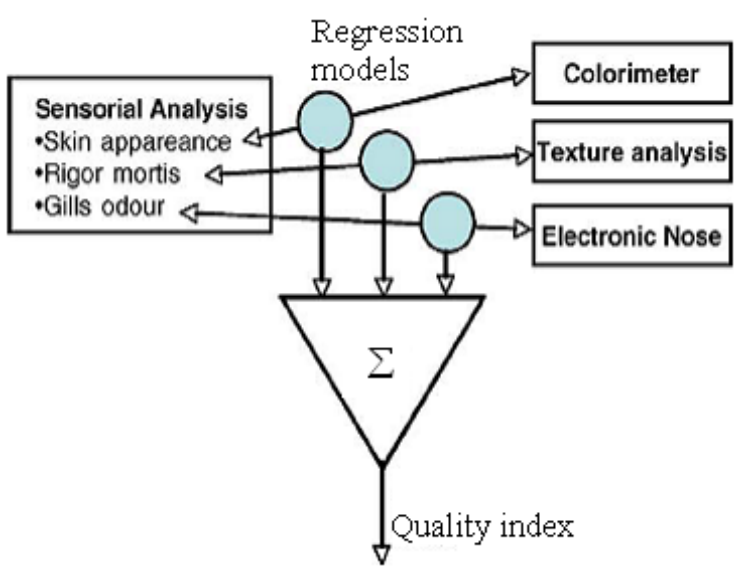

Fig. 2: The conceptual scheme underlying the artificial quality index built on the signals of different instrumental techniques. Texture analysis, colorimeter and electronic nose are used, after a proper calibration, the sensorial perception related to rigor mortis of flesh, skin appearance and gill odour, respectively. Estimated attributes are the simply summed in order to provide a synthetic indicator of fish freshness
However currently, instrumental evaluation had take over most of the sensorial evaluation by human. This is because the estimation of quality of fish based on traditional measures can be difficult. The method to determine the quality parameters of fish are also often complicated and time consuming and the result are often obtained after the product have been distributed to the consumer. Compared to the evaluation by using the instruments was much more faster, easy to handle, has the ability to carry out many samples as routine and more reliable compare to human evaluation even though they are trained.

Figure 2 shows the conceptual scheme underlying the artificial quality index built on the signals of different instrumental techniques.

Methods of the correlation between fish freshness and change in $\mathbf{p H}$ : According to Kyrana et al. ${ }^{[4,13]}$ they had measured a 5:1, water : fish homogenate, using a glass electrode at $20^{\circ} \mathrm{C}$. At the end of the experiments, the results of changes in $\mathrm{pH}$ over the period of iced storage are shown in Table 1 and 2.

Table 1: Changes in $\mathrm{pH}$, moisture and fat content, free fatty acid (FFA) and thiobarbituric acid (TBA) value in gilthead sea beam over the period of iced storage ${ }^{[13]}$

\begin{tabular}{llllll}
\hline Days in ice & $\mathrm{pH}$ & Moisture $^{\mathrm{l}}$ & Fat $^{1}$ & FFA $^{2}$ & TBA-value $^{3}$ \\
\hline $0^{6}$ & $6.20(0.05)^{\mathrm{A}}$ & $70.30(0.30)^{\mathrm{A}}$ & $7.69(0.17)^{\mathrm{A}}$ & $\mathrm{ND}$ & $0.67(0.05)^{\mathrm{AC}}$ \\
1 & $6.12(0.04)^{\mathrm{B}}$ & $70.50(0.51)^{\mathrm{A}}$ & $7.83(0.16)^{\mathrm{A}}$ & $\mathrm{ND}$ & $0.67(0.06)^{\mathrm{AC}}$ \\
3 & $6.10(0.30)^{\mathrm{B}}$ & $71.85(0.47)^{\mathrm{B}}$ & $6.58(0.26)^{\mathrm{B}, \mathrm{C}}$ & $2.19(0.11)^{\mathrm{A}}$ & $0.79(0.13)^{\mathrm{A}, \mathrm{B}, \mathrm{C}}$ \\
6 & $6.10(0.02)^{\mathrm{B}}$ & $\mathrm{ND}$ & $\mathrm{ND}$ & $\mathrm{ND}$ & $\mathrm{ND}$ \\
7 & $\mathrm{ND}$ & $72.20(0.26)^{\mathrm{B}}$ & $6.68(0.08)^{\mathrm{B}}$ & $2.52(0.13)^{\mathrm{B}}$ & $0.62(0.05)^{\mathrm{A}}$ \\
9 & $6.22(0.05)^{\mathrm{A}}$ & $72.50(0.34)^{\mathrm{B}}$ & $6.37(0.06)^{\mathrm{C}}$ & $2.92(0.03)^{\mathrm{C}}$ & $0.93(0.11)^{\mathrm{B}, \mathrm{D}, \mathrm{F}}$ \\
11 & $6.35(0.05)^{\mathrm{C}}$ & $73.55(0.22)^{\mathrm{C}}$ & $6.22(0.19)^{\mathrm{C}}$ & $3.33(0.34)^{\mathrm{C}, \mathrm{D}}$ & $0.96(0.08)^{\mathrm{D}, \mathrm{E}}$ \\
13 & $\mathrm{ND}$ & $\mathrm{ND}$ & $\mathrm{ND}$ & $\mathrm{ND}$ & $\mathrm{ND}$ \\
14 & $6.45(0.05)^{\mathrm{D}}$ & $72.00(0.35)^{\mathrm{B}}$ & $6.72(0.13)^{\mathrm{B}}$ & $3.67(0.29)^{\mathrm{D}}$ & $0.76(0.03)^{\mathrm{C}, \mathrm{D}}$ \\
17 & $6.50(0.06)^{\mathrm{D}, \mathrm{E}}$ & $\mathrm{ND}$ & $\mathrm{ND}$ & $\mathrm{ND}$ & $0.91(0.04)^{\mathrm{D}}$ \\
21 & $6.57(0.05)^{\mathrm{E}, \mathrm{F}}$ & $72.20(0.18)^{\mathrm{B}}$ & $6.18(0.02)^{\mathrm{C}}$ & $9.01(0.10)^{\mathrm{E}}$ & $1.17(0.03)^{\mathrm{E}}$ \\
24 & $6.60(0.03)^{\mathrm{F}}$ & $72.40(0.40)^{\mathrm{B}}$ & $6.65(0.09)^{\mathrm{B}}$ & $6.20(0.018)^{\mathrm{F}=}$ & $1.07(0.03)^{\mathrm{F}}$ \\
\hline
\end{tabular}

${ }^{1} \mathrm{~g}$ per $100 \mathrm{~g}$ flesh; ${ }^{2} \mathrm{~g}$ oleic per $100 \mathrm{~g}$ fat; ${ }^{2} \mathrm{mg}$ malonaldehyde per kg flesh; ${ }^{2}$ approximately $4 \mathrm{~h}$ after harvesting. Date are mean values; figures in brackets represent standard deviation, $\mathrm{n}-3$. Means within the same column with different superscripts are significantly $(\mathrm{p}<0.05)$ different. ND-not determined.

Table 2: Changes in $\mathrm{pH}$, trimethylamine oxide (TMAO) and volatile bases, free fatty acid (FFA) and thiobarbituric acid (TBA) value in European sea bass over the period of iced storage $\mathrm{e}^{[4]}$

\begin{tabular}{|c|c|c|c|c|c|c|}
\hline Days in ice & $\mathrm{pH}$ & TMAO $^{*}$ & TMA-N ${ }^{*}$ & TVB-N ${ }^{*}$ & $\mathrm{FFA}^{\dagger}$ & TBA-value ${ }^{\$}$ \\
\hline 1 & $6.39(0.04)^{\mathrm{A}, \mathrm{B}}$ & $22.08(0.28)^{\mathrm{A}}$ & $0.20(0.02)^{\mathrm{A}}$ & $17.22(0.42)^{\mathrm{A}}$ & $1.78(0.04)^{\mathrm{A}}$ & $0.37(0.02)^{\mathrm{A}}$ \\
\hline 4 & $6.34(0.02)^{\mathrm{A}}$ & $20.25(0.43)^{\mathrm{B}}$ & $0.23(0.01)^{\mathrm{A}}$ & $16.46(0.30)^{\mathrm{B}}$ & $1.85(0.04)^{\mathrm{B}}$ & $0.45(0.02)^{\mathrm{B}}$ \\
\hline 8 & $6.35(0.05)^{\mathrm{A}, \mathrm{B}}$ & $18.38(0.33)^{\mathrm{C}}$ & $0.27(0.02)^{\mathrm{B}}$ & $17.56(0.39)^{\mathrm{A}}$ & $2.09(0.06)^{\mathrm{C}}$ & $0.55(0.03)^{\mathrm{C}}$ \\
\hline 12 & $6.41(0.01)^{\mathrm{B}, \mathrm{C}}$ & $16.51(0.32)^{\mathrm{D}}$ & $0.40(0.02)^{\mathrm{C}}$ & $18.98(0.30)^{\mathrm{C}}$ & $3.21(0.09)^{\mathrm{D}}$ & $0.62(0.03)^{\mathrm{D}}$ \\
\hline 15 & $6.46(0.03)^{\mathrm{C}}$ & $15.15(0.27)^{\mathrm{E}}$ & $0.64(0.03)^{\mathrm{D}}$ & $22.93(0.47)^{\mathrm{D}}$ & $9.87(0.11)^{\mathrm{E}}$ & $0.55(0.03)^{\mathrm{C}}$ \\
\hline 19 & $6.56(0.02)^{\mathrm{D}}$ & n.d. & $0.92(0.03)$ & $24.78(0.53)^{\mathrm{E}}$ & $3.31(0.05)^{\mathrm{D}}$ & $0.58(0.03)^{\mathrm{C}, \mathrm{D}}$ \\
\hline 22 & $6.69(0.04)^{\mathrm{E}}$ & $12.55(0.38)^{\mathrm{F}}$ & $1.25(0.04)^{\mathrm{F}}$ & $30.58(0.52)^{\mathrm{F}}$ & $2.73(0.07)^{\mathrm{F}}$ & $0.65(0.02)^{\mathrm{D}}$ \\
\hline
\end{tabular}


Table 1 Changes in $\mathrm{pH}$, moisture and fat content, Free Fatty Acid (FFA) and Thiobarbituric Acid (TBA) value in gilthead sea beam over the period of iced storage ${ }^{[13]}$.

The low muscle $\mathrm{pH}$ early in the period of iced storage reflected the good nutritional state of fish. The low $\mathrm{pH}$ values encountered a few hours after harvesting may also indicate that the fish was not harvested in arrested state and that they have been stressed. The first $\mathrm{pH}$ measurements were made four hours after the death of the fish. The glycogen in the muscle would have been metabolised to lactic acid by then and would account for the low found. The typical $\mathrm{pH}$ of live fish muscle $\approx 7.0$. During the initial storage period the $\mathrm{pH}$ was consistently low (less than 6.2) and this may have contributed to the increased shelf-life of the fish used in this trial. However, at the end of the first week of storage $\mathrm{pH}$ started to increased, reaching a value of 6.6 by the end of the trial. The increase in $\mathrm{pH}$ value of 6.6 by the end of the trial. The increase in $\mathrm{pH}$ values after day 7 reflected the production of alkaline bacterial metabolites in spoiling fish and coincided with the increase in Total Volatile Basic Nitrogen (TVBN) ${ }^{[13]}$. During the first half of the edible storage life of iced sea bass there were no significant changes in $\mathrm{pH}$. The increase in $\mathrm{pH}$ after day 12 was associated with the state of rapid spoilage of the fish ${ }^{[4]}$.

Table 2 Changes in $\mathrm{pH}$, Trimethylamine Oxide (TMAO) and volatile bases, Free Fatty Acid (FFA) and Thiobarbituric Acid (TBA) value in European sea bass over the period of iced storage ${ }^{[4]}$.

Most of the researchers in this area focus on fish that is normally and commonly consumed by the local peoples in their place. Most of the fish samples are the salt water and fresh water raw fish freshly harvested from the farm or the sea. For example the commonly used types of fish samples are gilthead sea beam ${ }^{[14]}$, Sardina pilchardus ${ }^{[12]}$, Coregonus albula L. ${ }^{[5]}$, Merluccius merluccius ${ }^{[16]}$, silver cat fish ${ }^{[16]}$, Mallotus Villosus $^{[17]}$, Thunnus obesus ${ }^{[18]}$, Sepia officinalis ${ }^{[19]}$.

\section{CONCLUSION}

The correlation of $\mathrm{pH}$ towards the freshness of fish had been shown clearly in Table 1 and 2 . We can conclude that $\mathrm{pH}$ can act as indicators of the fish freshness as it start with low reading at the early stage of storage which means the nutritional state was still good and then increased when the fish had been stored for certain period of time. So, by checking the $\mathrm{pH}$ of the fish after a certain period of storage can determine the state of it freshness.
However, the success of future development of new analytical tools is always dependent on a synergism of technologies e.g. the multivariate methods, sample handling procedure and instrumental aspects, which together can provide analytical tool to improve the speed and accuracy of the current available techniques. Thus, the mathematical data handling should be included into the list of vital technologies in the product development of food quality assays.

\section{REFERENCES}

1. Olafsdottir, G., P. Nesvadba, C.D. Natale, M. Careche, J. Oehlenschlager, S.V. Tryggvadottir, Schubring, M. Kroeger, K. Heia, Esaiassen, A. Macagnano and B.M. Jorgensen, 2004. Multisensor for fish quality determination. J. Trends Food Sci. Technol., $\quad 5: \quad 86-93 . \quad$ DOI: 10.1016/j.tifs.2003.08.006

2. Oehlenschlanger, J., 1998. Sensory evaluation in inspection. Proceeding of the final meeting of the concerted action "evaluation of fish freshness" ' 98 , Institute International du Froid, Paris, pp: 363-368.

3. Abbas, K.A., S.M. Sapuan and A.S. Mothtar, 2006. Shelf life assessment of Malaysian Pangasius sutchi during cold storage. J. Sãndhanã., 31: 635643. DOI: 10.1007/BF02715919.

4. Kyrana, V.R. and V.P. Lougovious, 2002. Sensory, chemical and microbiological assessment of farm raised European sea-bass (Dicentrarchus Labrax) stored in melting ice. Int. J. Food Sci. Technol., 37: 319-328. DOI: 10.1046/j.1365-2621.2002.00572.x.

5. Raatikainen, O., V. Reinikainen, P. Minkkinen, T. Ritvanen, P. Muje, J. Pursiainen, T. Hiltunen, P. Hyvonen, A. Von Wright and S. Reinikainen, 2005. Multivariate modelling of fish freshness index based on ion mobility spectrometry measurements. J. Analytica Chim. Acta., 544: 128134. DOI: $10.1016 /$ j.aca.2005.02.029.

6. Bremner, H.A. and M. Sakaguchi, 2000. A critical look at whether "freshness" can be determine. J. Aquatic Food. Prod. Technol., 9: 5-25. http://direct.bl.uk/bld/PlaceOrder.do?UIN=086451 $748 \&$ ETOC $=$ RN\&from $=$ searchengine.

7. Olafsdottir, G., E. Martinsdottir, P. Dalgaard, B. Najensen, I. Undeland, I.M. Mackie, G. Henehen, Nielsen and Nilsen, esvadba. 1997. Method to evaluate fish freshness in research and industry. J. Trend Food Sci. Technol., 8: 258-265. DOI: 10.1016/S0924-2244(97)01049-2.

8. Codex guidelines for the sensory evaluation of fish and shelfish in laboratories. CAC-GL 31-1999. www.codexalimentarius.net/download/standards/3 59/CXG_031e.pdf. 
9. Ansari, F.A. Abbas, K.A. and M.M.H. Ahmad, 2004. A Correlation between thermal diffusivity variation and quality of cold preserved fish. Asian J. Sci. Technol. Develop., 21: 1-10.

10. Wilkie, K., M. Wootton and J.F. Paton, 2004. Sensory testing of Australian fragrant, imported fragrant and non-fragrant rice aroma. Int. J. Food Prop., 2: 27-36. DOI: 10.1081/JFP-120022493.

11. Simeonidou, S., A. Govaris and K. Vareltzis, 1998. Quality assessment of seven Mediterranean fish species during storage on ice. J. Food Resear. Int., 30: 479-484. DOI: 10.1016/S0963-9969(98)00008-8.

12. Macagnano, A., M. Careche, A. Herrero, R. Paolesse, E. Martinelli, G. Pennazza, P. Carmona, A.C.D. D'Amico, natale, 2005. A model to predict fish quality from instrumentals features. J. Sens. Actuat., 112: 293-298.

DOI: 10.1016/j.snb.2005.06.028.

13. Kyrana, V.R., V.P. Lougovious and D.S. Valsamis, 1997. Assessment of shelf-life of maricultured gilthead sea bream (Sparus aurata) stored in ice. Int. J. Food Sci. Technol., 32: 339-347. DOI: 10.1046/j.1365-2621.1997.00408.x.

14. Gil, L., J.M. Barat, E. Garcia-Breijo, J. Ibanez, R. Martinez-Manez, J. Soto, E. Llobet, J. Brezmes, M.C. Aristoy and F. Toldra, 2008. Fish freshness analysis using metallic potentiometric electrodes. J. Sens. Actuat., 131: 362-370.

DOI: 10.1016/j.snb.2007.11.052.

15. Pastoriza, L., M. Bernardez, G. Sampedro, M.L. Cabo and J.J.R. Herrera, 2008. Use of terile and ozonized water as a strategy to stabilize the quality of stored refrigerated fresh fish. J. Food Contr., 19: 772-780. DOI: 10.1016/j.foodcont.2007.08.003.
16. Miron, D., S. Dos, B. Moraes, A.G. Becker, M. Crestani, R. Spanevello, V.L. Loro and B. Baldisserotto, 2008. Ammonia and $\mathrm{pH}$ effects on some metabolic parameters and gill histology of silver catfish, Rhamdia quelen (Heptapteridae). J. Aquacult., 277: 192-196. DOI: 10.1016/j.aquaculture.2008.02.023.

17. Hjalmarsson, G.H., J.W. Park and K. Kristbergsson, 2007. Seasonal effects on the physiochemical characteristics of fish sauce made from capelin (Mallotus villosus). J. Food Chem., 103:495-504.

DOI: 10.1016/j.foodchem.2006.08.029.

18. Ruiz-Capillas, C. and A. Moral, 2005. Sensory and biochemical aspects of quality of whole bigeye tuna (Thunnus obesus) during bulk storage in controlled atmospheres. J. Food Chem., 89: 347354. DOI:10.1016/j.foodchem.2004.02.041.

19. Pires, P.V., P. Seixas, M. Mota, J. LapaGuimaraes, J. Pickova, A. Lindo and T. Silva, 2008. Sensory, microbiological, physical and chemical properties of cuttlefish (Sepia officinalis) and broadtail shortfin squid (Illex coindetti) stored in ice. J. LWT., 41: 1655-1664.

DOI: 10.1016/j.lwt. 2007.10. 003. 